RITOS TRADICIONALES DIERON UN MAYOR REALCE A LA CONCENTRACIÓN ARAUCANA (1938)

Diario Austral 


\section{Ritos tradicionales dieron un mayor realce a la concentración araucanina}

El domingo último se efectuó en Boroa, gran conceatración araucana orgunizada por Caja Central Indigena con motivo de auiversar

Se celebraron un guillatum y un auhun

Como se ha venido informando, el aonisiso 18 se realizó Concentracion Indigena en conniemoracion de ha numero de asistentes y ta forma cómo so desenvolvieron los dis unton actow det prosrama que previanente se liabia otaturado. Dende las primeras horas de 12 masianas so noto un inusita do de indizenas en grandes grupos de a caballo, caravanas de rretas non muchas mujeres indikenas CEICA DE DOS MIL ASISTFNTTES

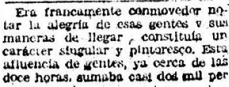

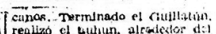

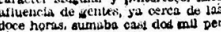
NUMERosos visitavtes

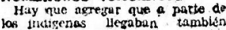
gar da culllaturn conde sq habia

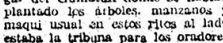

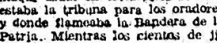
neles galopaban ep sus capalgadu muchos frar yculareses simpacizante nóviles conio en kamiones y do
aballo. Se notabu ja jresencla de

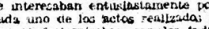

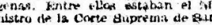

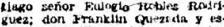

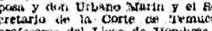
de Ninisis, el abogado don Asmend col y blempre qiredector del luaga

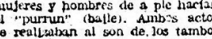

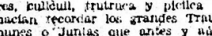

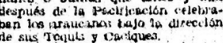

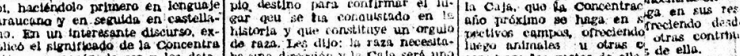

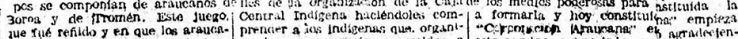

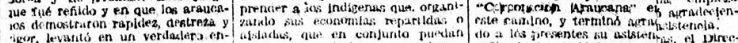

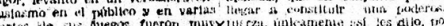

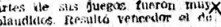

ONTERENCLA

Terminadus los juegos, $l=d$ asist

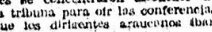

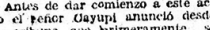
ntrezarian las pemesos at las qu de chues: y de futbol. A los chille adia uno de ellios una cambieta d alvarino 11 medallgs de plata. Ina ovaclón entro los assistenic

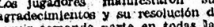

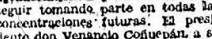
vor jes agradecto su valuo so concuCelracion nesultara mAs brHlan
UABLAN LOS DIAICENTES

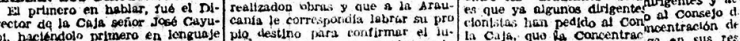
ALATÉzzo Baso

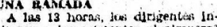
y su razón de ber y los deta. ba una direiviós y la caja zera uñ

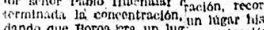

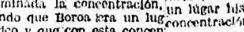

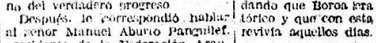

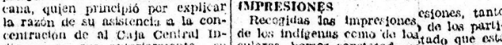

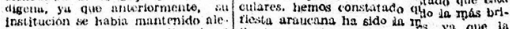

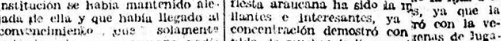

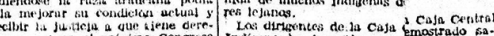

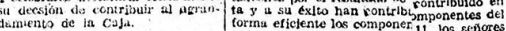

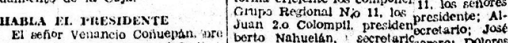

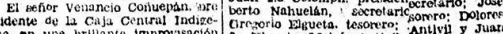

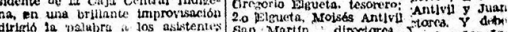
anliestandoles con cnergia ia

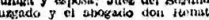

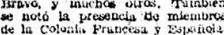

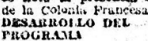

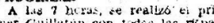

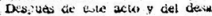

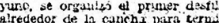

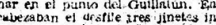
digenas portindu orü de elios

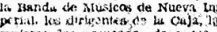
por thtimo los indigenas mon Mientras se crectuluba el disfil
Lego at carnjo de coneentracion

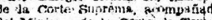

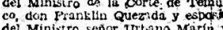
del Mecretorio de lit corio. par el presidente de In Caja $\mathrm{CrD}$ tral Indigena doa venansio coniue fiest Lel y terminamo dise y concentr

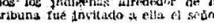

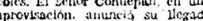

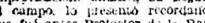

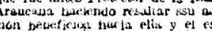

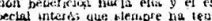

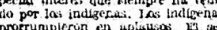

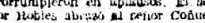

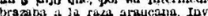
lado a gimirzar on el campo durante vas els esiada estuvo to

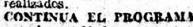

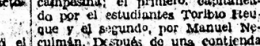

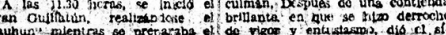

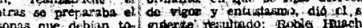
en parte en aquel acto soiemn renies del Grupo Reslonal de Jo

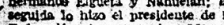
eseraclion Araucase don Acanyel ie nabia nreparud

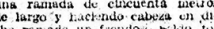

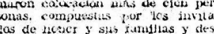

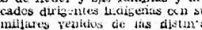

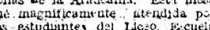
dustrial y E Eicuet. Agricula o Luego jas de calaberia forina-

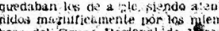

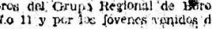
El golpe do vista que ofrecia est nulthud. era vendaderamente esrla y. satisficoction de dos tadigenas SEGUNDO GRAN DESFUE cill. cle to unutruca y clario se or

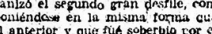
nniero $v$ entustassno que demos res como nourina de a ple y de

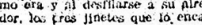

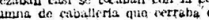

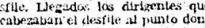
munado $\&$ detride $y$ can sus compo crrados las cuatro laterales do

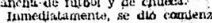
4. vartldo de Rútbol entre los clubs a la Juwentud Estudtantll de Te compuesto par jurentud todicens goals y Juventace Isstudlantili 2. con el club Galvarno, de Imperial 


\section{RITOS TRADICIONALES DIERON UN MAYOR REALCE A LA CONCENTRACIÓN ARAUCANA \\ DIARIO AUSTRAL (1938)}

Temuco; 21-12-1938

Ritos tradicionales dieron un mayor realce a la concentración araucana. El domingo último se efectuó en Boroa, gran concentración araucana organizada por Caja Central Indígena con motivo de aniversario. Se celebraron un guillatum y un auhun.

Como se ha venido informando, el domingo 18 se realizó la Concentración Indígena en conmemoración de la fundación de la Caja Central Indígena y ella constituyó un verdadero éxito por el número de asistentes y la forma cómo se desenvolvieron los distintos actos del programa que previamente se había elaborado.

Desde las primeras horas de la mañana, se notó un inusitado entusiasmo en el campo de Concentración, notándose la llegada de indígenas en grandes grupos de a caballo, caravanas de carretas con muchas mujeres indígenas que, desde lejanas tierras quisieron asistir a la fiesta de la Caja.

\section{CERCA DE DOS MIL ASISTENTES}

Era francamente conmovedor notar la alegría de esas gentes y sus maneras de llegar, constituía un carácter singular y pintoresco. Esta afluencia de gentes, ya cerca de las doce horas, sumaba casi dos mil personas.

\section{NUMEROSOS VISITANTES}

Hay que agregar que a parte de los indígenas llegaban también muchos particulares simpatizantes y amigos de la raza, tanto en automóviles como en camiones y de a caballo. Se notaba la presencia de distinguidas damas y caballeros que se interesaban entusiastamente por cada uno de los actos realizados y que confraternizaban con los indígenas. Entre ellos estaban el Ministro de la Corte Suprema de Santiago, señor Eulogio Robles Rodríguez; don Franklin Quezada y esposa y don Urbano Marín y el Secretario de la Corte de Temuco; profesores del Liceo de Hombres y de Niñas, el abogado don Armando Zúñiga y esposa; Juez del Segundo Juzgado y el abogado don Renato Bravo, y muchos otros. También se notó la presencia de miembros de la Colonia Francesa y Española. 


\section{DESARROLLO DEL PROGRAMA}

A las 7 horas, se realizó el primer Guillatun con todas las ritualidades del caso.

Después de este acto y del desayuno, se organizó el primer desfile alrededor de la cancha para terminar en el punto del Guillatun. Encabezaban el desfile tres jinetes indígenas portando uno de ellos la Bandera Nacional; venían después, la Banda de Músicos de la Nueva Imperial, los dirigentes de la Caja, las mujeres, los araucanos de a pie y por último los indígenas montados.

\section{DON EULOGIO ROBLES}

Mientras se efectuaba el desfile, llegó al campo de concentración el señor Eulogio Robles R., Ministro de la Corte Suprema, acompañado del Ministro de la Corte de Temuco, don Franklin Quezada y esposa del Ministro señor Urbano Marín y del Secretario de la Corte.

Los visitantes fueron recibidos por el presidente de la Caja Central Indígena don Venancio Coñuepan, quien les dio la bienvenida y les agradeció su presencia en esta fiesta indígena. Presencio una parte del y terminado éste y concentrados los indígenas alrededor de la tribuna fue invitado a ella el señor Robles. El señor Coñuepan, en una improvisación, anuncio su llegada al campo, lo presentó recordando que fu antes Protector de la Raza Araucana haciendo resaltar su noción beneficios hacia ella y el especial interés que siempre ha tenido por los indígenas. Los Indígenas irrumpieron en aplausos. El señor Robles abrazo al señor Coñuepan y dijo que, por su intermedio abrazaba a la raza araucano. Invitado a almorzar en el campo condecoración, accedió gustoso y durante toda su estada estuvo tomando nota de los diferentes actos realizados.

\section{CONTINÚA EL PROGRAMA}

A las 11:30 horas, se inició el gran Guillatún, realizándose el "auhun” mientras se preparaba el grupo de personas que debían tomar parte en aquel acto solemne. En primer término oraron los dirigentes del Grupo Regional de Boroa, señores Juan $2^{\circ}$ Colompil, los hermanos Elgueta y Nahuelán; en seguida lo hizo el presidente de la Federación Araucana don Manuel Aburto Panguilef y por último los dirigentes de la Caja Central señores Venancio Coñuepan, José Cayupi, Avelino Ovando, (no se lee), Pablo Huichalaf. Una actitud solemne y profundamente respetuosa había en todos los asistentes, mientras se hacía este Guillatun, rito tradicional de los araucanos. 
Terminado el Guillatún, se realizó el auhun, alrededor del lugar del Guillatún donde se habían plantado los árboles, manzanos y maqui usual en estos ritos al lado estaba la tribuna para los oradores y donde flameaba la Bandera de la Patria. Mientras los cientos de jinetes galopaban en sus cabalgaduras efectuando el auhun, en el centro y siempre alrededor del lugar del Guillatún y de la tribuna, las mujeres y los hombres de a pie hacían el "purrun" (baile). Ambos actos se realizaban al son de los tambores, cullcull, trutruca y pifilca y hacían recordar los grandes Trahunes o Juntas que antes y aun después de la Pacificación celebraban los araucanos bajo la dirección de sus Toquis y Caciques.

\section{ALMUERZO BAJO UNA RAMADA}

A las 13 horas, los dirigentes invitaron a asistentes al almuerzo campestre que le había preparado.

En la mesa se honor, situada bajo una ramada de cincuenta metros de largo y haciendo cabeza en dicha ramada un frondoso boldo, tomaron colocación más de cien personas, compuestas por los invitados de honor y sus familias y destacados dirigentes indígenas con sus familiares venidos de las distintas zonas de la Araucanía. Esta masa fue magníficamente atendida por los estudiantes del Liceo, Escuela Industrial y Escuela Agrícola de Temuco.

Luego los de la caballería formaban un gran circulo en dos flas y quedaban los de a pie, siendo atendidos magníficamente por los miembros del Grupo Regional de Boroa $\mathrm{N}^{\circ} 11$ y por los jóvenes venidos de otros grupos.

El golpe de vista que ofrecía este almuerzo, compuesto d una gran multitud, era verdaderamente espectacular y se podía notar la alegría y satisfacción de los indígenas asistentes.

\section{SEGUNDO GRAN DESFILE}

A las 15 horas y al toque dl cullcull, d la trutruca y el clarín se organizó el segundo gran desfile, componiendo en la misma forma que el anterior y que fue soberbio por el número y entusiasmo que demostraban los desfilantes, tantos mujeres como hombres de a pie y de a caballo. Siendo grande la cancha como era y al desfilarse a su alrededor, los tres jinetes que lo encabezaban casi se tocaban con la columna de caballera que cerraba el desfile. Llegados los dirigentes que encabezan el desfile al punto donde estaba la tribuna, se dio por terminado el desfile y con sus componentes quedaron automáticamente cerrados los cuatro laterales de la cancha de fútbol y de chueca. 
Inmediatamente, se dio comienzo al partido de fútbol entre los clubs de la Juventud Estudiantil de Temuco y el Roble Huacho, éste último compuesto por juventud indígena campesina; el primero capitaneado por el estudiante Toribio Reuque y el segundo, por Manuel Neculmán. Después de una contienda brillante en que se hizo derroche de vigor y entusiasmo, dio el siguiente resultado: Roble Huacho 2 goals y Juventud Estudiantil 1.

Al ganador le correspondió jugar con el Club Galvarino, de imperial, capitaneado por el señor Andrés Huenul.

El juego de estos equipos resultó parejo en el tiempo reglamentario y por tanto no hubo victoria, por lo que debió jugarse un tiempo extra de 10 minutos y en este último caso resultó vencedor el Club Galvarino. Simultáneamente con este segundo partido de fútbol se realizaba también el juego araucano del "chueca", los equipos se componían de araucanos de Boroa y de Tromén. Este juego fue reñido y en que los araucanos demostraron rapidez, destreza y rigor, levantó en un verdadero entusiasmo en el público y en varias partes de sus juegos fueron muy aplaudidos. Resultó vencedor el Boroa.

\section{CONFERENCIAS REALIZADAS}

Terminados los juegos, los asistentes se concentraron alrededor de la tribuna para oír las conferencias que los dirigentes araucanos iban a dar.

Antes de dar comienzo a este acto el señor Cayupi anunció desde la tribuna que primeramente se entregarían los premios a los que resultaron victoriosos en el juego de chueca y de fútbol. A los chuequeros boroanos se entregó a cada uno de ellos una camiseta de polo; a los futbolistas del equipo Galvarino 11 medallas de plata.

La entrega de premios arrancó una ovación entre los asistentes. Los jugadores manifestaron sus agradecimientos y su resolución de seguir tomando parte en todas las concentraciones futuras. El presidente don Venancio Coñupan, a su vez les agradeció su valioso concurso que contribuyó para que la concentración resultar más brillante.

\section{HABLAN LOS DIRIGENTES}

El primero en hablar fue el Director de la Caja señor José Cayupi, haciéndolo primero en lenguaje araucano y en seguida en castellano. En un interesante discurso, explicó el significado de la Concentración y su razón de ser y los detalles de la organización de la Caja Central indígena haciéndole comprender a los indígenas que, organizando sus economías repartidas o aisladas, que en conjunto puedan llegar a constituir una poderosa fuerza, únicamente así les dijo, podemos avanzar o entrar en el camino verdadero progreso. 
Después le correspondió hablar al señor Manuel Aburto Panguilef, presidente de la Federación Araucana, quien principió por explicar la razón de su asistencia a la concentración de la Caja Central Indígena, ya que anteriormente su institución se había mantenido alejada de ella y que había llegado al convencimiento que solamente uniéndose la raza araucana podía ella mejorar su condición actual y recibir la justicia a que tiene derecho y que el próximo Congreso a celebrarse declararía oficialmente su decisión de contribuir al agrandamiento de la Caja.

\section{HABLA EL PRESIDENTE}

El señor Venancio Coñoepan, presidente de la Caja Central indígena, en una brillante improvisación dirigió la palabra a los asistentes manifestándole con energía, la necesidad y conveniencia que había para la raza araucana, de llegar a convertir a la Caja en una poderosa entidad, ya que el verdadero mérito se demostraba solamente realizando obras y que a la Araucanía le correspondía labrar su propio destino para confirmar el lugar que se ha conquistado en la historia y que constituye un orgullo de raza. Les dijo: la raza necesitaba una dirección y la Caja será uno de los medios poderosos para llegar a formarla y hoy constituida la "Corporación Araucana" empieza este camino, y terminó agradeciendo a los presentes su asistencia.

Siendo las 16:30 horas, el Director señor Pablo Huichalaf dio por terminada la concentración, recordando que Boroa era un lugar histórico y que con esta concentración revivía aquellos días.

\section{IMPRESIONES}

Recogidas las impresiones, tanto de los indígenas como de los particulares, hemos constatado que esta fiesta araucana ha sido la más brillantes e interesantes, ya que la concentración demostró con la venida de muchos indígenas de lugares lejanos.

Los dirigentes de la Caja Central Indígena se ha demostrado satisfechos por el resultado de la fiesta y a su éxito han contribuido en forma eficiente los componentes del Grupo Regional N ${ }^{\circ} 11$. Los señores Juan $2^{\circ}$ Colompil, presidente; Alberto Nahuelán, secretario; José Gregorio Elgueta, tesorero; Dolores $2^{\circ}$ Elgueta, Moisés Antivil y Juan San Martín, directores. Y debe mencionarse también al señor Ignacio Curiqueo, presidente del Grupo más cercano a Boroa.

Un detalle que demuestra con elocuencia cuánto se ha adentrado entre los araucanos esta fiesta, es que ya algunos dirigentes y accionistas han pedido al Consejo de la Caja, que la Concentración del año próximo se haga en sus respectivos campos, ofreciendo desde luego animales u otras contribuciones para los gastos de ella. 